\title{
The Exploring of Animation Movie Subtitles Translation Strategies with Skopos Theory Perspective
}

\author{
Mingxin Zheng ${ }^{1}$ \\ ${ }^{1}$ Jilin Animation Institute, Changchun, Jilin Province, China
}

Keywords: Skopos theory perspective, the animation, film subtitles, English translation.

\begin{abstract}
Film as a powerful tool to spread culture is increasingly influencing our life. Film subtitles translation in increasing influx of foreign movies and a lot of translation plays an important role in the subtitle is a kind of important means of communication to promote cultural exchanges. This paper tries to study from the perspective of skopos theory in subtitle translation, this paper discusses the characteristics and purpose of subtitle translation, combined with examples based on the analysis of the specific film put forward the corresponding translation strategies, including literal translation, liberal translation and cut method, for scholars interested in make a further research in the field of subtitle translation.
\end{abstract}

\section{Introduction}

As the global integration process accelerating, communication between Chinese and western culture and influence has been strengthened. Film is way of cultural communication with transmitted, universality and the mass media. With the speeding up of reform and opening up and further, the importance of the film subtitles translation is crucial, for us to get information, learning a foreign language, etc. [1]. That resulted from the introduction of foreign movies in English-Chinese translation, the translation of subtitles dominate evolved into Chinese films abroad leading to Chinese-English translation of subtitle translation gradually formed the mainstream, but also by the original domestic foreign language film development to appear in English original films about Chinese traditional culture.

As China's economy has flourished and intercultural communication has deepened, Chinese people have more access to western animated films nowadays. That will be encountered by the audience, animated film s play a significant role [1]. Animated film s serves multiple functions, for example, it can transfer much information to the audience: the genre, the theme and background information. A brilliant animated film can also entertain the audience aesthetically, and being attracted by this, audience will be called upon to buy tickets to enjoy the animated film. Translation of the English Animated film s is necessary for better promotion of the animated films in Chinese film market, because not all the audience can appreciate the original version.

\section{Description of skopos theory}

Translation skopos theory, beginning in Germany in the 1970 s, is an important theory of Germany in the functional school of translation theory; it is generally passed through three periods of development. For the first time, les proposed priority should be given to the functional characteristics of the translation, therefore, translation should have specific requirements, and her thoughts laid the foundation of skopos theory (X.T. Fan 2002:25 to 28) [2]. The second period, Vermeer founded the skopos theory; translation is to follow the first principle is "objective laws". The period of the further development is the skopos theory. Her theory focus is to study the behavior of the translation process and translation strategies must be determined by the intended purpose. Is the skopos theory, translation is a purposeful act. The purpose of translation, therefore, before the start of the translation behavior is clearly defined, so as to decide what kind of translation strategies of skills, text of the desired function. 


\subsection{Teleological principle of purpose.}

Skopos theory argues that all translation activities follow the first principle is the principle of "purpose", namely the translation should be able to in the target language context and culture, according to the target language receiver anticipated way. Translation actions to achieve the purpose of the decision process of the whole translation behavior, namely the decision method [2]. Usually, "purpose" refers to the communicative purpose of the translation, namely "translation in translating chattering social and cultural context of the target language readers the communicative function of". Vermeer as a result, the translator should be in a given context clear its specific purpose, and according to this purpose to decide what kind of translation methods, literal translation, free translation, or somewhere in between.

\subsection{Consistency principle.}

Coherence refers to the coherent within the language of the translation must conform to the standard, inner coherence requires subtitle translation, can make the recipient understands and is significant in the context of culture and communication, and conform to the cultural background [3]. Fidelity principle refers to the original and the relationship between the translations. In fact is faithful to the original, but the purpose of translation and translator's understanding of the original decision on the loyal degree and form.

\subsection{Loyalty principle.}

Nords find teleology has two defects: one is the people of different cultural backgrounds have different opinions of good translation, so peculiar to cultural translation mode. 2 it is required by the goal of the translation and the original contrary intention of the author, therefore, nords are loyalty principle was proposed to solve the difference of different culture background and the relationship between the translation behaviors of the participants [4]. This means that to consider the intentions of all participants and expectations. Translators should respect the original author and the author intention, did have an obligation to explain everything. Thus, the loyalty principle main concern in the process of translation the translator and the author, the receiver, and so the relationship between the participants.

In a word, the three principles constitute the basic principles of translation skopos theory, but the continuity principle and the principle of faithfulness principles must be obeyed in purpose, this is the first principle of skopos theory.

\section{Animation film subtitle translation}

This thesis probes into animated film translation from Skopos theory, which was proposed by German translator Hans Vermeer. In the light of Skopos theory, translation is defined as a purposeful activity as well as an intentional communication between cultures [3]. "The end justifies the means" is the essence of this theory, which means the purpose of the translation decide the strategies adopted. It lays the emphasis on the purpose of translation activity, functions of the target text, the addressees'communicative situation, and empowers more initiative and freedom to the translators. This thesis argues that Skopos theory can be applied as the theoretical basis for animated film translation [4]. Under the guidance of Skopos theory, translators can adopt appropriate translation techniques to make the animated film tittles perform informative, cultural, aesthetic and vocative function in a more effective way, so that it can stir up audience's attention, curiosity and interest, and finally achieve the Skopos of calling upon them to appreciate the animated film to boom the box office.

The basic characteristics of the film and television lies in the subtitle language processing, is also said that subtitle translation need and text express, associated with the general translation of written expression is very different. Therefore, film translation has the mass, instantaneity, time and space restriction, intercultural communication, etc. 


\subsection{The mass of easy to understand.}

Popular for the audience, is to satisfy their need to be able to understand, to understand, simple sentence, the dialogue of the basically comes from life, can let the general audience, so the film subtitles should conform to the public education level, at the same time, it must be easy to understand, fluency, catchy, and pay attention to colloquial [4].

\subsection{Time and space is restricted.}

In time, because subtitles appear and disappear the beginning and the end should talk to characters unifies, this makes the translator must be for a limited time will people want to express emotion to convey to the audience [5]. In space, subtitles are to point to appear at the bottom of the screen foreign literal translation or annotations, so need to have certain restrictive on the space. These restrictions require the translator to be within a certain time and space to the characters' feelings show incisively and vividly, so clear and concise, easy to understand, for both young and old Yidu reach become a necessary condition of subtitle translation.

\subsection{Cross-cultural communication.}

Language is a cross-cultural communicative activity, it is not only the language of communication, is the fusion of culture. Different language expression way, way of thinking and behavior way represents the different language and culture background [5]. So the translation of film and television culture in the process of cultural exchange has a quite important role. Is an important part of film translation, subtitle translation subtitles of film and television works can let the audience in a short period of time to get the most amount of information, can bring the convenience of viewing to the audience at the same time can also let them enjoy the quality of film and television works.

\section{Animation film subtitles translation strategy}

Subtitle translation is a kind of way of intercultural communication, the role of basically has two: as I mentioned earlier, is to provide more information, to make the audience more understanding of the development of the plot 2 it is to help the hearing or intellectually disabled person to read and understand the content of the film and television [6]. Subtitle translation is a relatively new field, it detracts from the achievement, however, in theory, specification, film and television subtitle translation theory has not yet been mature and perfect; in practice, the quality of subtitle translation needs to be improved.

As a kind of audio image art, different from other kinds of works of art, it doesn't like books, newspapers, readers can scan can know the effect, thus attracted by the story. Film translation of film and television culture between Chinese and western communication plays a vital role. In the study of film translation, if can keep the film text, on the basis of general characteristics, the film subtitles translation of behavior and its huge role in the movie marketing combination, can better to complete the film subtitle translation [6]. With the rapid development of the industry and the improvement of marketization degree, the development of the film, there is a special and more. Therefore, film translation should break the traditional, constantly adapt to the development of the new situation. However, strengthening the commercial value of film translation must be in the movie art, culture and aesthetic value, on the basis of not blind pursuit of commercial value and the treasure of the crystallization of discarding the art, culture and language unique charm.

\subsection{Reflect the characteristics of film subtitles.}

Characteristics of film and television language lie in its listening, comprehensive, instantaneity, popularity and no note. Comprehensive is refers to the actor's dialogue by the actor's speaking at three in the shape of the mouth, pause and gestures that restriction, and subtitle translation has also been corresponding constraints; Momentariness requires translation is concise, fluent, smooth and fluent [6]; Without a note does not allow the translators for annotations in addition add subtitles or narrator in the dubbed film. In general, the subtitle translation should follow the principle of "shrinkage, 
straight, Jane".

\subsection{Literal translation.}

Literal translation is to try to keep the original author of language form, subtitle to the time space limit, determines its translation is different from other culture. Subtitle translation requirements as far as possible simple to understand, use simple sentences and compression long sentence to limit the length of the subtitles, let the audience understand reaction in the fastest time, rather than undermine its integral atmosphere of entertainment, reach the expected purpose of subtitle translation [7].

\subsection{Semantic translation method.}

Subtitle translation should be easy to understand, concise and vivid, clear smooth, but as a result of two kinds of language there are differences between Chinese and western culture, the content of cultural information processing, in respect of the film art types, characters, language style, on the basis of focusing on the audience's cognitive ability and appreciation habit. In the subtitle translation of "Jurassic park", the translator mainly USES the free translation strategy, enables the audience to better understand the film director to express Chinese culture and thought [6]. The important principle of free translation is the language for text processing, attaches' great importance to the translation effect pay attention to the reader's response.

In the process of translation, the translator must respect the characteristics of the target language, to excavate the expression of the target language as much as possible of potential, because language can express our thought by means of the rich [7]. The primary task of translation is to make the reader see the translation can be clear at a glance. That is to say, readers can understand without the source language culture background. This requires as little as possible in the translation copy blunt loan words, as much as possible to use belongs to accept language expression.

\subsection{Statements reduction method.}

Cut type strategy refers to the translator should fully consider the public's cultural background, values, language habits and other factors, on the basis of from the perspective of the target language, in the "cognitive judgment on the basis of the audience, in the limited time and space or even some irrelevant cognitive activities related to abridge the information strategy, to highlight the correlation stronger information" [7]. So cut method is often used in subtitle translation process of a translation strategy, appropriate cuts the information in the source language, let the audience in a short time, easy to experience in the movie scene and artistic conception.

\subsection{Before and after the statement coordinate method.}

People need to be careful when translated subtitles. The same script, by many individual segments translation respectively, whether to take the literal translation, or liberal translation, both before and after to do care of each other. Every translator must see the whole movie, knowing the entire plot [8]. Because some of the sentences need to translate to know the whole story, elephant, the explanation may be wrong. Such as sister a word, you can be translated into "sister, elder sister, female members, sister, sister", the "female members, nuns," you can judge at that time. But what exactly is the elder sister or younger sister? We must not blindly turn into a "sister". Watch the film, some age difference can be seen from the appearance, but there are close in age, it is difficult to judge. Some film translation into two people, one which cd1, cd2, and it is the tip about the age in which cd1, so responsible for translation of $\mathrm{cd} 2$, if not seen which cd1, will not be able to make the right judgment. And the result of random translation will give the audience accept increase the difficulty. They are the people translation error-prone, bad person names, place names, address, etc.

The word such as the district attorney in the film appeared many times. Can merge translated as "public" and "inspector", or the two word translation respectively, interpreted as "local lawyer", "da" and "local inspector general", who say the translation of drama influence is not too big. If many people translation, must turn into something [8]. The audience will see thought it was quite a few people. Some working group for the rush, the translation of a lot of hits when all people, each person is responsible for hundreds of words, first unified all person names, place names, specialist is 
responsible for the final proof read an English subtitles and Chinese subtitles. In reason, many hands make light work, so the subtitle should be very perfect. But some people in the striker web download the Lord of the rings 3 subtitles, faced with a lot of translation version of the BBS, and ultimately chose a net friend of subtitles. So choose, is not think of the Internet English than other strongmen [8]. The key is extremely serious, his attitude to the translation and translation is one independent, can grasp every detail, from the overall situation to ensure the unification of the translation language style. Mentioned here language style, is refers to the translation of each person's expression is different. More than more than in the process of translation, translation, proofreading can ensure subtitle error reduction, shorter time, but it is difficult to guarantee the unity of the whole translation language style. So many translations of subtitle translation methods to do before and after care unified repeated nouns and language style.

\section{Conclusion.}

Summary to say, if you want to do English film subtitles translation accurate and vivid, first, to keep the style of the original English films, the specific strategy can be summarized as: accurate understanding of the original, so as to correctly convey the meaning; Master the primitive culture background, thus appropriate translation; Master the relevant professional knowledge in the film, cautious to deal with these difficulties in translation; To know proper nouns, and conform to the translation norms. Second, adopting reasonable translation methods, the specific strategy can be summarized as: literal translation, remains in the English original vivid; Liberal translation, so as to better solve the differences between English and Chinese two languages; Care of before and after the law, we should try to be more than translation in details before and after unification. Believe that if some strategies translators do as mentioned above, which will reflect the original in the artistic effect.

\section{References}

[1] B.J. Hua, Inheritance and transcendence: functional translation skopos theory research, Beijing: China social sciences press, 2008, vol. 4, pp. 61-64.

[2] X.T. Fan, Theories on translation purpose, translation in China, 2002 vol. 6, pp. 25-27.

[3] C.Q. Huang, The perspective of the tentative study skopos theory in English-Chinese film subtitle translation, Shanghai Jiaotong University, 2007, vol. 4, pp. 14-16.

[4] Y.X. Li, The film subtitle translation strategy of translation in China, 2001, vol.7, pp.38-40.

[5] N.L. Liu, Film titles and subtitles translation studies, Film and literature, 2005, vol. 5, pp. 15-19.

[6] Zh. Ch. Qian, Film translation becomes more and more important in the garden, the Chinese translation, 2000, vol.1, pp. 24-26.

[7] X. Tan, Translation Studies, Foreign language teaching and research press, 2005, vol. 9 pp. 12-14.

[8] T.Y. Ma, from relevance theory perspective subtitle translation, Ocean university of China, 2007 vol.1, pp. 43-48. 